\title{
ANTI-COAGULANT PROPERTIES OF FLAVONOID COMPOUNDS: POTENTIAL STRUCTURE-FUNCTIONAL RELATIONSHIP
}

\author{
PHISIT POUYFUNG ${ }^{1}$, SURIYAN SUKATI ${ }^{2}$ \\ ${ }^{1}$ Division of Occupational Health and Safety, School of Public Health, Walailak University, Nakhon Si Thammarat 80161, Thailand. \\ ${ }^{2}$ Department of Medical Technology, School of Allied Health Sciences, Walailak University Nakhon Si Thammarat 80161, Thailand. \\ Email: suriyan.su@wu.ac.th
}

Received: 30 October 2019, Revised and Accepted: 25 December 2019

ABSTRACT

Objective: Flavonoids, naturally-occurring compounds in fruits and vegetables, possess anti-coagulant property. However, a very few studies were attempted to understand how flavonoid structure influences its anti-coagulation property, such as clotting time. In this study, we investigated structurally similar flavonoid compounds which differ in the number of hydroxyl groups and compared their anti-coagulation properties.

Methods: We selected and evaluated five flavonoid compounds, that is, chrysin, apigenin, luteolin, kaempferol, and quercetin, for their anti-coagulant properties using in vitro prothrombin time (PT) assays and activated partial thromboplastin time (APTT) assay.

Results: Our findings suggested that quercetin, kaempferol, and luteolin showed a significant anti-coagulant effect on APTT (p<0.05) in a dosedependent manner. The dose of $500 \mu \mathrm{M}$ quercetin showed potent prolong APTT with $37.43 \pm 1.60 \mathrm{~s}$, followed by $500 \mu \mathrm{M}$ of kaempferol and luteolin (34.63 $\pm 1.29 \mathrm{~s}$ and $4.83 \pm 1.56 \mathrm{~s}$, respectively). Furthermore, a combination of $500 \mu \mathrm{M}$ of quercetin with $0.25 \mathrm{U} / \mathrm{ml}$ of heparin demonstrated prolong APTT $(52.16 \pm 5.18 \mathrm{~s})$ when compared with individual effects of either $0.25 \mathrm{U} / \mathrm{ml}$ heparin $(33.4 \pm 0.50 \mathrm{~s})$ or $500 \mu \mathrm{M}$ quercetin (37.43 $\pm 1.62 \mathrm{~s})$ alone.

Conclusion: Our results demonstrated that numbers of the hydroxyl group on flavonoid compounds influence anti-coagulation properties. In addition, the prolonged APTT assay results suggested that quercetin, kaempferol, and luteolin could affect factors VIII, IX, XI, and XII of intrinsic pathway. Moreover, the synergistic effect of quercetin further enhances the heparin anti-coagulation effect. Based on our findings, we recommend that the consumption of vegetables and fruits rich in quercetin, luteolin, and kaempferol could help prevent thrombotic stroke in high-risk patients.

Keywords: Flavonoids, Quercetin, Activated partial thromboplastin time assay, PT assay, Anti-coagulant.

(C) 2021 The Authors. Published by Innovare Academic Sciences Pvt Ltd. This is an open access article under the CC BY license (http://creativecommons. org/ licenses/by/4.0/) DOI: http://dx.doi.org/10.22159/ijap.2021.v13s1.Y0050. Journal homepage: https://innovareacademics.in/journals/index.php/ijap

\section{INTRODUCTION}

Non-communicable diseases, including diabetes mellitus (DM) and hypertension (HT), have been increased in both developing and developed countries [1]. DM and HT are well-established risk factors for stroke, wherein pathological conditions worsen blood vessel damage and stimulate excessive blood clotting [2-4]. In contrast, blood clotting is an important event during trauma and other vascular damages, where it plays pivotal role to stop bleeding and consequently seals up vascular damage, thus prevent blood loss. Two primary blood clotting pathways are (1) intrinsic pathway (factors VIII, IX, XI, and XII) and (2) extrinsic pathway (factor VII). Both pathways induce fibrin clot formation [5-7]. Patients with DM and HT are being treated with warfarin, heparin, and aspirin to prevent blood clotting and thus avoid life-threatening stroke condition [8]. In contrast, long-term use of these medical drugs on anti-coagulant treatment caused hemorrhagic risk [9]. This study was conducted to explore anti-coagulant ability of natural flavonoid compounds, and their potential being a safer alternative to prescribed anti-coagulant drugs.

Flavonoids, a natural-occurring compounds in fruits and vegetables, have been known for anti-platelet and anti-coagulant properties, both in vitro and in vivo [10]. However, the structure-functional relationship and possible mechanistic role of flavonoids as an anti-coagulant agent are not well studied. Our objective of this study was to investigate and compere the effect of flavonoids (chrysin, apigenin, luteolin, kaempferol, and quercetin) on the hemostasis through extrinsic and intrinsic pathways using in vitro prothrombin time (PT) assays and activated partial thromboplastin time (APTT) assay, respectively. In this study, we investigated anti-coagulant properties of flavonoids with different numbers of hydroxyl groups. We also investigated potential synergetic effect of flavonoids and a low dose of heparin, which can confirm if eating a diet rich in fruits and vegetables containing flavonoids could promote stroke prevention in hypertension and diabetic patients [11].

\section{MATERIALS AND METHODS}

Chemicals and reagents

Chrysin, apigenin, luteolin, kaempferol, and quercetin were purchased from Sigma-Aldrich (St. Louis, MO, USA). The chemical structures are shown in Fig. 1. Dimethyl sulfoxide (DMSO) was obtained from Merck (MA, USA).

\section{Blood sampling and plasma preparation}

Ten milliliters of venous blood samples were obtained from healthy volunteers without a history of bleeding or thrombosis $(n=10$, aged 18-30 years) according to human blood collection which was approved by the Office of the Human Research Ethics Committees of Walailak University (protocol no. WUEC-18-024-01). Venous blood samples were transferred to blood collection tube (BD Vacutainer ${ }^{\circledR}$ sodium citrate tubes, Becton, Dickinson and Company, Franklin Lakes, NJ) containing $0.105 \mathrm{M}$ sodium citrate $(9: 1 \mathrm{v} / \mathrm{v}$, blood: anti-coagulant) and then subjected to centrifugation $\left(800 \mathrm{~g}, 10 \mathrm{~min}\right.$, and $\left.25^{\circ} \mathrm{C}\right)$. The supernatant plasma was transferred to a new tube and stored at $-80^{\circ} \mathrm{C}$ until use.

PT activity assay

PT assays were carried out following the coagulometer protocols as previously described [12] with modifications for each sample using 
<smiles>O=c1cc(-c2ccccc2)oc2cc(O)cc(O)c12</smiles>

Chrysin<smiles>O=c1cc(-c2ccc(O)cc2)oc2cc(O)cc(O)c12</smiles>

Apigenin<smiles>O=c1cc(-c2ccc(O)c(O)c2)oc2cc(O)cc(O)c12</smiles>

Luteolin<smiles>O=c1c(O)c(-c2ccc(O)cc2)oc2cc(O)cc(O)c12</smiles>

Kaempferol<smiles>O=c1c(O)c(-c2ccc(O)c(O)c2)oc2cc(O)cc(O)c12</smiles>

Quercetin

Fig. 1: The chemical structures of test compounds

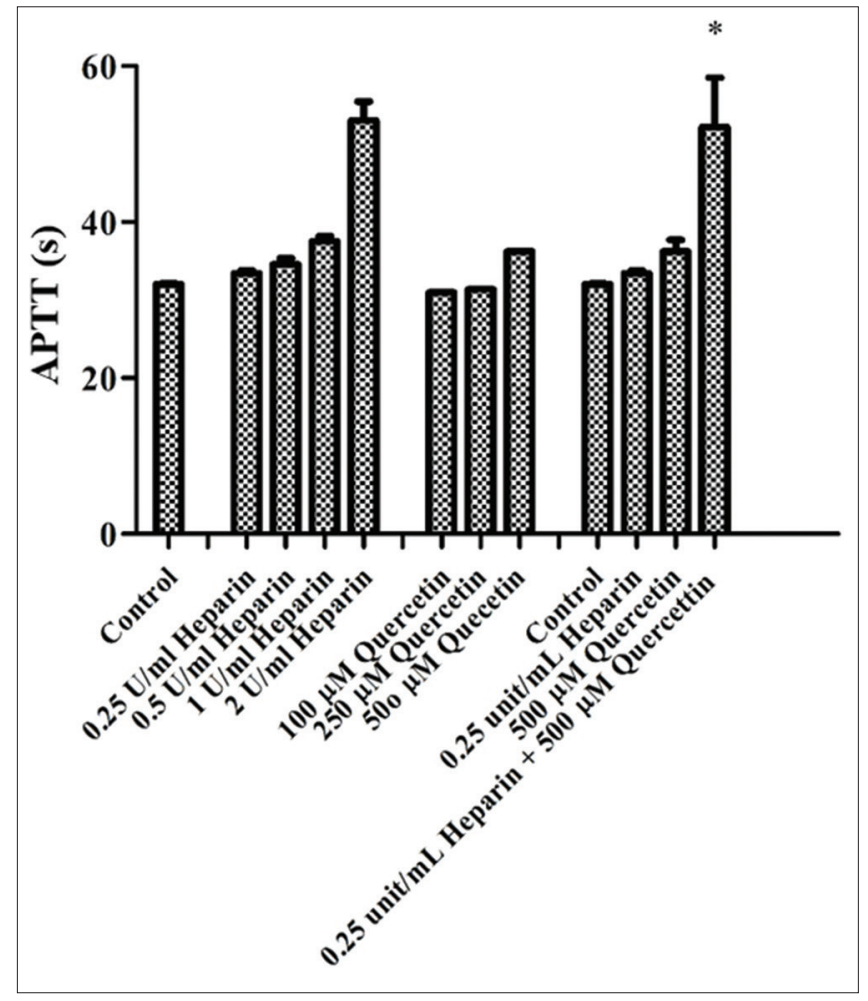

Fig. 2: Combined effect of quercetin and heparin on APTT assay. ${ }^{*} \mathrm{p}<0.05$, compared to individual effects $(0.25 \mathrm{U} / \mathrm{ml}$ heparin and $500 \mu \mathrm{M}$ quercetin)

an automatic coagulation instrument (Humaclot Duo Plus, HUMAN, Wiesbaden, Germany). Briefly, $90 \mu \mathrm{l}$ of plasma sample was incubated with $10 \mu \mathrm{l}$ of test compounds (Chrysin, apigenin, luteolin, kaempferol, and quercetin) diluted in normal saline (final concentration of 250 and $500 \mu \mathrm{M}, 37^{\circ} \mathrm{C}$ ). After $5 \mathrm{~min}$ pre-incubation, $100 \mu \mathrm{l}$ of PT assay reagent (Thromborel ${ }^{\otimes}$ S, Siemens Healthcare Diagnostics Products GmbH, Germany) were added to initiate the reaction sassy and the clotting time was measured. One percent DMSO was used as vehicle control and heparin $(2 \mathrm{IU} / \mathrm{ml})($ Cristalia $®$, Itapira, SP, Brazil) was used as a positive control.
Table 1: Effect of flavonoids on anti-coagulant activity based on PT and APTT of normal human plasma

\begin{tabular}{llll}
\hline Compounds & Concentrations & PT $^{(\mathbf{s})^{\mathbf{a}}}$ & ${\text { APTT }(\mathbf{s})^{\mathrm{a}}}^{\mathrm{a}}$ \\
\hline Vehicle control & $0.5 \% \mathrm{DMSO}$ & $15.23 \pm 0.05$ & $32.03 \pm 0.20$ \\
Heparin (Positive & $1 \mathrm{IU} / \mathrm{ml}$ & $14.60 \pm 0.57$ & $37.50 \pm 0.96$ \\
control) & $2 \mathrm{IU} / \mathrm{ml}$ & $15.70 \pm 0.37$ & $53.00 \pm 3.48$ \\
& $3 \mathrm{IU} / \mathrm{ml}$ & $17.53 \pm 0.24$ & $>200$ \\
Chrysin & $250 \mu \mathrm{M}$ & $15.07 \pm 0.41$ & $31.87 \pm 0.67$ \\
& $500 \mu \mathrm{M}$ & $14.50 \pm 0.00$ & $32.40 \pm 0.21$ \\
Apigenin & $250 \mu \mathrm{M}$ & $14.83 \pm 0.65$ & $32.03 \pm 0.20$ \\
& $500 \mu \mathrm{M}$ & $14.40 \pm 0.36$ & $33.06 \pm 0.95$ \\
Luteolin & $250 \mu \mathrm{M}$ & $13.83 \pm 0.05$ & $29.83 \pm 1.01$ \\
& $500 \mu \mathrm{M}$ & $14.10 \pm 0.57$ & $34.83 \pm 1.56^{*}$ \\
Kaempferol & $250 \mu \mathrm{M}$ & $14.25 \pm 0.05$ & $31.20 \pm 0.28$ \\
& $500 \mu \mathrm{M}$ & $13.90 \pm 0.50$ & $34.63 \pm 1.29^{*}$ \\
Quercetin & $250 \mu \mathrm{M}$ & $14.70 \pm 0.20$ & $31.37 \pm 0.21$ \\
& $500 \mu \mathrm{M}$ & $6.30 \pm 0.85$ & $37.43 \pm 1.60^{*}$ \\
\hline
\end{tabular}

${ }^{a}$ Mean \pm SD $(n=10) .{ }^{*} \mathrm{p}<0.05$, compared with the vehicle control group.

PT: Prothrombin time, APTT: Activated partial thromboplastin time

\section{APTT activity assay}

In APTT activity assay, $90 \mu \mathrm{l}$ of plasma sample collected from human volunteers were mixed with $10 \mu \mathrm{l}$ of test compound (final concentration of 250 and $500 \mu \mathrm{M}$ ) at $37^{\circ} \mathrm{C}$. After $5 \mathrm{~min}$, pre-warmed aPTT reagent (Actin ${ }^{\circledR}$ FS APTT, Siemens Healthcare Diagnostics Products GmbH, Germany) was added to the mixture. Clotting time was measured after the addition of $50 \mu \mathrm{l}$ of $\mathrm{CaCl}_{2}$ solution using automated coagulometer (Humaclot Duo Plus, HUMAN, Wiesbaden, Germany). One percent DMSO was used as vehicle control and $1 \mathrm{IU} / \mathrm{ml}$ heparin (Cristalia ${ }^{\circledR}$, Itapira, SP, Brazil) was used as a positive control.

\section{Statistical analysis}

All data were expressed as means \pm SD of three measurements. Statistical comparisons of the prolonged time between test compounds and vehicle control (1\% DMSO) were achieved by non-parametric indecent t-test using GraphPad Prism version 5.0 (San Diego, California). p-value $<0.05$ was considered statistically significant.

\section{Anti-coagulation assays}

Although flavonoids have been reported to prolong anti-coagulant effect on human blood sample - both in vitro and in vivo, the structurefunctional relationship of flavonoids (e.g., chrysin, apigenin, luteolin, kaempferol, and quercetin) has not been studied. We first determined 
whether the prolongation of APTT and PT was due to the structurefunctional relationship of chrysin, apigenin, luteolin, kaempferol, and quercetin on healthy volunteer blood samples. All these flavonoids share the same backbone structure and differ in numbers of hydroxyl groups primarily. To differentiate the anti-coagulant mechanistic properties of flavonoids through extrinsic and/or intrinsic pathways, PT and APTT assays were performed, respectively. In PT and APTT assays, each flavonoid was incubated with a human blood sample for $5 \mathrm{~min}$ with different final concentrations of 250 and $500 \mu \mathrm{M}$ and prolonged PT and APTT time were measured. As shown in the Table 1, an average PT and APTT on healthy volunteers were $15.23 \pm 0.05 \mathrm{~s}$ and $32.03 \pm 0.20 \mathrm{~s}$, respectively. Heparin was used as a positive control in this study. The results of PT and APTT assays demonstrated that flavonoids contained the higher anti-coagulant effect on APTT compared to PT assay, thus indicating that these flavonoids might interfere with intrinsic clotting cascade. Among test compounds, luteolin, kaempferol, and quercetin showed a significantly prolonged time of APTT assay in a dose-dependent manner. The dose of $500 \mu \mathrm{M}$ quercetin showed the potent prolong APTT ( $37.43 \pm 1.60 \mathrm{~s})$, followed by $500 \mu \mathrm{M}$ of kaempferol $(34.63 \pm 1.293 \mathrm{~s})$ and luteolin $(4.83 \pm 1.56 \mathrm{~s})$.

\section{The combined anti-coagulant effect of quercetin and heparin}

Among flavonoids tests, quercetin exhibited the potent anti-coagulant activity against APTT assay. It is thus, we further determined the combined anti-coagulant effect of quercetin and heparin (a prescribed drug for anti-coagulant), whether a reduced dose of heparin in blood clotting formation. We then combine the low dose of heparin $(0.25 \mathrm{U} / \mathrm{ml})$ with the various concentration of quercetin $(100,250$, and $500 \mu \mathrm{M}$ ) in healthy blood plasma before the addition of anti-coagulant agent. The dose of $0.25 \mathrm{U} / \mathrm{ml}$ of heparin and $500 \mu \mathrm{M}$ of quercetin could prolong aPTT with $52.16 \pm 5.18 \mathrm{~s}$ when compared to individual effects $(0.25 \mathrm{U} / \mathrm{ml}$ heparin $(33.4 \pm 0.50)$ and $500 \mu \mathrm{M}$ quercetin $(37.43 \pm 1.62)$ ) (Fig. 2) suggesting that quercetin and heparin might have synergistic effects against blood clotting.

\section{DISCUSSION}

In the present study, we first determined the anticoagulant effect of flavonoids including chrysin, apigenin, luteolin, kaempferol, and quercetin, (all are naturally occurring flavonoid compounds found abundantly in the fruits in vegetables) on blood samples collected from healthy volunteers. Our results demonstrated anti-coagulant effect of luteolin, kaempferol, and quercetin on blood clotting through APTT assay, but not PT assay. These contrasting outcomes indicated that flavonoids could affect the intrinsic coagulation pathway and not extrinsic pathway.

On the beginning of the $21^{\text {st }}$ century, the number of patients with noncommunicable diseases, including DM, HT, and stroke, has been increased from time to time [1-3]. These diseases could damage blood vessel and finally, blood clotting formation, leading to morbidity and mortality associated with stroke and cardiovascular [13]. Alternative medicines, such as herbal medicines, have been considered as a good source of anticoagulant agents [14]. At present, anti-coagulation research community is focused on identifying plant-based materials with anti-coagulant activities, to prevent early stroke recurrence during blood vessel damage in DM and HT patients [14]. Flavonoids, natural-occurring substances in fruits and vegetables, have been focused and previously been reported containing anti-coagulant effect both in vitro and in vivo.

Based on our results, where potent inhibitory effect of quercetin on clotting formation was observed, we further studied and determined that the combined effect of quercetin and heparin was more effective. As shown in Fig. 2, at low concentration of heparin $0.25 \mathrm{IU} / \mathrm{ml}$ contained low anti-coagulant activity; however, when we mixed 0.25 $\mathrm{IU} / \mathrm{ml}$ heparin together with $500 \mu \mathrm{M}$ quercetin, the prolonged clotting time is significantly increased compared to either $500 \mu \mathrm{M}$ quercetin or $0.25 \mathrm{IU} / \mathrm{ml}$ heparin alone. The synergistic effect could be contributed due to differences in the mechanism of action of quercetin and heparin. Heparin reversibly binds to antithrombin III in the intrinsic pathway, resulting in the inactivation of blood clotting [15], whereas quercetin potentially interferes with complex VIII and XI activity. Complex VIII and XI play a role in the intrinsic blood clotting cascade [16]. Therefore, we believe that the different anti-coagulation activation targets of heparin and quercetin potentially increase the prolonged time of APTT assay.

As shown in Table 1, chrysin and apigenin, which contain 2 and 3 hydroxyl groups, respectively, did not confer anti-coagulant activity. However, luteolin and kaempferol, containing 4 hydroxy groups, have shown increased prolonged clotting time, and quercetin containing 5 hydroxy groups exhibited the most potent anti-coagulant effect in our findings. The data clearly suggested that the number of hydroxyl groups in the flavonoids could potentially contribute to anti-coagulation properties. Our current finding is supported by previous study, where Manolove et al. demonstrated that the position of the hydroxyl group in other non-flavonoid molecules confers anti-coagulant activity of the compounds [15]. The results of prolonged APTT implied that luteolin, kaempferol, and quercetin may affect factors VIII, IX, XI, and XII in the intrinsic pathway. This result is similar to the previous report of Kuntic et al., 2011 that rutin (quercetin-3-rutinoside) has been shown to inhibit factors VIII and IX of the intrinsic pathway [17].

\section{CONCLUSION}

We demonstrate that quercetin possesses the highest anticoagulant properties among tested flavonoids. We also demonstrated that the numbers of hydroxyl group in flavonoid compounds could affect their anti-coagulant properties. Based on our data and findings, we propose that consumption of vegetables and fruits containing flavonoids (including quercetin, luteolin, and kaempferol) could potentially prevent thrombotic stroke, especially in the DM or HT patients. Moreover, eating flavonoid-abundant fruits and vegetables might help lower the use of prescribed drugs for stroke prevention in DM and HT. The in vivo study of combining quercetin with chemotherapeutic drugs, for example, heparin needs to be further elucidated.

\section{ACKNOWLEDGMENTS}

The authors would like to thank the financial support (Grant no. WU60307) from Walailak University, Nakhon Si Thammarat, Thailand. Authors would like to thank Dr. Harshul Pandit for proof-reading final manuscript draft.

\section{CONFLICTS OF INTEREST}

All authors have none to declare.

\section{REFERENCES}

1. World Health Organization. The Top 10 Causes of Death: Leading Causes of Death by Economy Income Group. 2016. Available from: https://www.who.int/news-room/fact-sheets/detail/the-top-10-causesof-death. [Last accessed on 2019 Oct 30].

2. Alloubani A, Saleh A, Abdelhafiz I. Hypertension and diabetes mellitus as a predictive risk factors for stroke. Diabetes Metab Syndr 2018;12:577-84.

3. Braunwald E. Diabetes, heart failure, and renal dysfunction: The vicious circles. Prog Cardiovasc Dis 2019;62:298-302.

4. Dokken BB. The pathophysiology of cardiovascular disease and diabetes: Beyond blood pressure and lipids. Diabetes Spectr 2008;21:160-5.

5. Alquwaizani M, Buckley L, Adams C, Fanikos J. Anticoagulants: A review of the pharmacology, dosing, and complications. Curr Emerg Hosp Med Rep 2013;1:83-97.

6. De Caterina R, Husted S, Wallentin L, Andreotti F, Arnesen H, Bachmann $\mathrm{F}$, et al. General mechanisms of coagulation and targets of anticoagulants (Section I). Position paper of the esc working group on thrombosis--task force on anticoagulants in heart disease. Thromb Haemost 2013;109:569-79.

7. Harter K, Levine M, Henderson SO. Anticoagulation drug therapy: A review. West J Emerg Med 2015;16:11-7.

8. Labuz-Roszak B, Machowska-Majchrzak A, Skrzypek M, Mossakowska M, Chudek J, Wiecek A, et al. Antiplatelet and anticoagulant therapy in elderly people with Type 2 diabetes 
mellitus in Poland (based on the PolSenior Study). Arch Med Sci 2017:13:1018-24

9. Shoeb M, Fang MC. Assessing bleeding risk in patients taking anticoagulants. J Thromb Thrombolysis 2013;35:312-9.

10. Xiao J. Dietary flavonoid aglycones and their glycosides: Which show better biological significance? Crit Rev Food Sci Nutr 2017;57:1874-905.

11. Welsby IJ, JonesWL, Arepally G, De Lange F, Yoshitani K, PhillipsBute B, et al. Effect of combined anticoagulation using heparin and bivalirudin on the hemostatic and inflammatory responses to cardiopulmonary bypass in the rat. Anesthesiology 2007;106:295-301.

12. Mao W, Li H, Li Y, Zhang H, Qi X, Sun H, et al. Chemical characteristic and anticoagulant activity of the sulfated polysaccharide isolated from Monostroma latissimum (Chlorophyta). Int J Biol Macromol 2009;44:70-4.
13. Piazza G, Goldhaber SZ, Kroll A, Goldberg RJ, Emery C, Spencer FA. Venous thromboembolism in patients with diabetes mellitus. Am J Med 2012;125:709-16.

14. Akram M, Rashid A. Anti-coagulant activity of plants: Mini review. J Thromb Thrombolys 2017;44:1-6.

15. Gray E, Hogwood J, Mulloy B. The anticoagulant and antithrombotic mechanisms of heparin. Handb Exp Pharmacol 2012;207:43-61.

16. Kuntic V, Filipovic I, Vujic Z. Effects of rutin and hesperidin and their $\mathrm{Al}(\mathrm{III})$ and $\mathrm{Cu}(\mathrm{II})$ complexes on in vitro plasma coagulation assays. Molecules 2011;16:1378-88

17. Manolove L, Moessmer CM, Nicolova I, Danchev N. Synthesis and anticoagulant activities of substituted 2,4-diketochromans, biscoumarins, and chromanocoumarins. Arch Pharm Chem. Life Sci 2006;339:319-26. 